of suggestions.

The strategic down-shift has disappointed some scientists. "It's really frustrating to talk about \$1-billion concepts" as if researchers hadn't already considered that, says Britney Schmidt, a planetary scientist at the Georgia Institute of Technology in Atlanta who worked on the Clipper idea. "If you want to do the best science out there, totally committed to by the community, this is the mission you send." Because the Clipper would carry a range of instruments, it could investigate subduction zones, explore plumes and respond to a variety of other research questions, says Prockter.

And in July, NASA asked planetary scientists to submit ideas for instruments they would like to see fly onboard a craft such as the Clipper, whatever the cost. Proposals are due by 17 October, and the agency plans to choose around 20 of them next April for further development.

Although NASA is worried about the overall cost of a Europa mission, it has money to spend in the short term. For each of the past couple of years, Congress has given the agency's planetary-sciences division tens of millions of dollars more than it asked for, and directed it to spend the money on Europa mission concepts. The drive is led by Congressman John Culberson (Republican, Texas), a Star Trek-quoting space enthusiast who sits on a powerful spending committee.

Europa researchers are happy to take advantage. "I'm frothing at the mouth in excitement," says Kattenhorn. "There is clearly so much more that we still need to learn about Europa." -

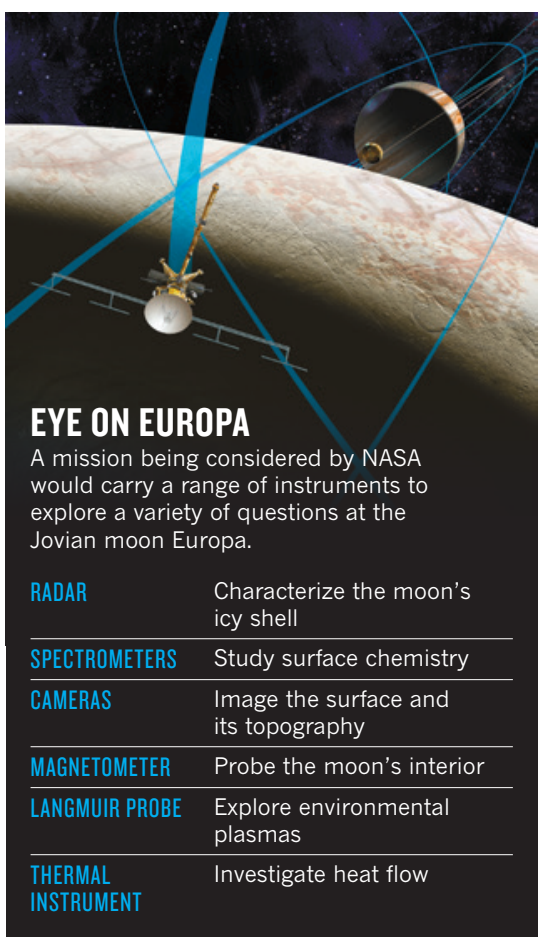

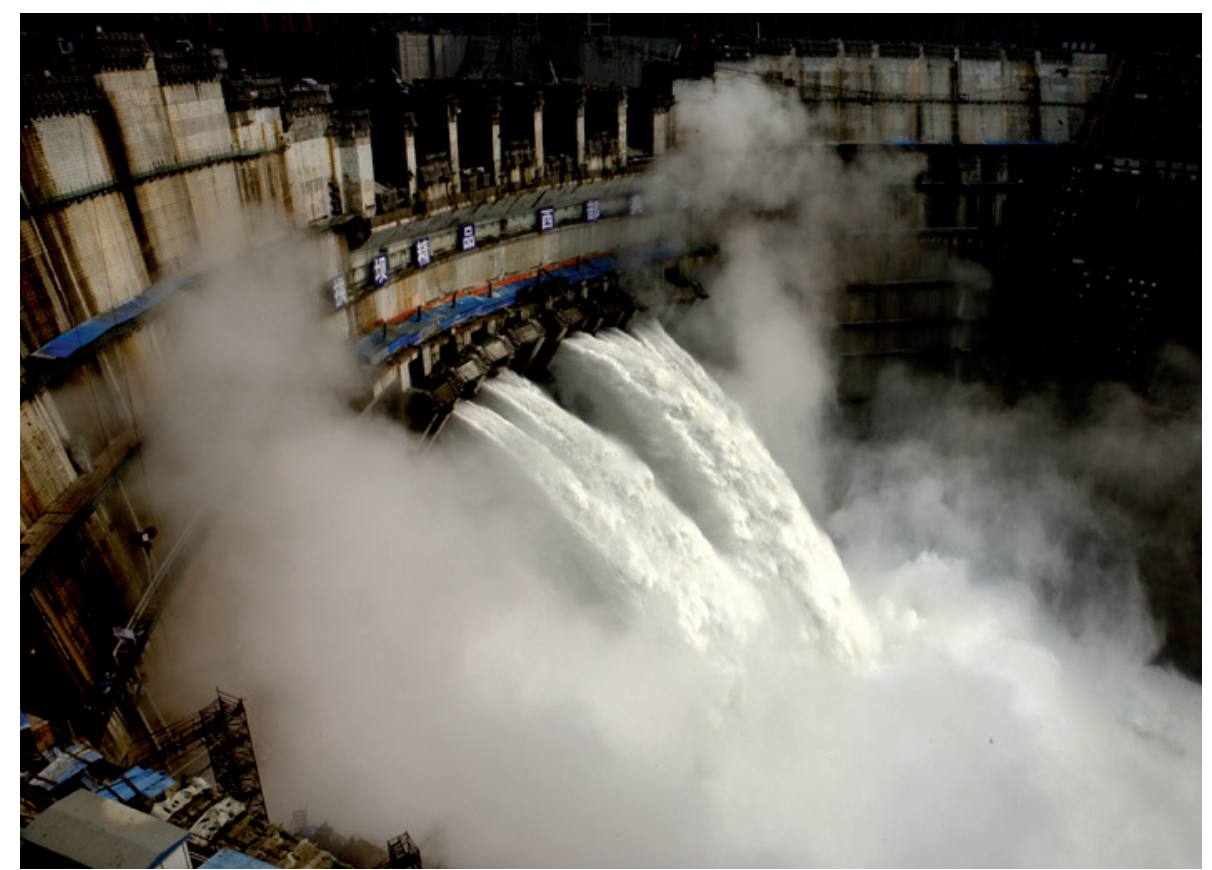

The Xiluodu hydropower station is sited directly over one of China's many fault lines.

\title{
HYDROPOWER
}

\section{Chinese data hint at trigger for fatal quake}

\section{Seismic activity started to rise just as two giant reservoirs on upper Yangtze were being filled with water.}

\section{BY JANE QIU}

$\mathrm{E}$ ver since 3 August, when an earthquake in southwestern China killed more than 600 people, the Chinese media and blogosphere have buzzed with speculation that the magnitude- 6.5 tremor was linked to the filling of two gigantic reservoirs along the upper Yangtze river. Now, a geologist says that he has data to support the possible link.

On 28 August, Fan Xiao, an engineer at the Sichuan Bureau of Geology and Mineral Resources in Chengdu, reported a rough correlation between the timing of the filling of the reservoirs and a rise in seismic activity in the surrounding region.

Posted on a website run by Probe International, a non-profit organization that reports on China's large-scale water projects, Fan's analysis is based on crude seismic data - the only sort that are publicly available - so the link is tentative. But "it's an important possibility", says Hu Xian-ming, a geophysicist at the Sichuan Earthquake Administration in Chengdu. "There are serious concerns for deadly quakes in the future."
Criss-crossed by active faults, the upper Yangtze region is seeing a boom in dam building for the generation of hydropower But when water flows quickly into the result ing reservoirs, it can change the stress on faults deep underground, either from the sheer weight of the water, or when water infiltrates the rocks through cracks and pores. These events might accelerate a fault's natural 'seismic clock', hastening an earthquake that is already building, or increase the chance of one occurring at all.

Debate is already raging about whether the 2008 quake in Wenchuan county, which killed at least 70,000 people (see Nature 459, 153-157; 2009) was linked to the filling of Zipingpu reservoir in Sichuan province. Fan was one of the first to raise the possibility, and his suggestion was followed up by other researchers who have reported, for instance, that the reservoir might have brought forward the occurrence of the quake by tens to hundreds of years (S. Ge et al. Geophys. Res. Lett. 36, L20315; 2009).

After the 3 August quake in Ludian county, discussion turned to two newly created 
reservoirs, the nearest of which, Xiluodu, is 40 kilometres from the epicentre (see 'Of dams and quakes').

On the basis of seismic readings taken between January 2010 and July 2014, Fan reports that small quakes became more frequent in late 2012 and continued until the end of the period. That heightened activity roughly correlates with the reservoirs being filled. The areas most affected cluster at three locations: one near each reservoir, and a third close to a fault whose rupture led to the latest quake. "The study has its limitations," says Fan, "but it does ring an alarm bell of increasing reservoir-triggered quakes in the region."

\section{A POSSIBLE TREND}

His report also flags up two smaller earthquakes that hit the county of Yongshan in April and August and were caused by faults directly below the Xiluodu reservoir. Xu Xi-wei, deputy director of the China Earthquake Administration's Institute of Geology in Beijing, agrees that these two tremors were "most likely triggered by

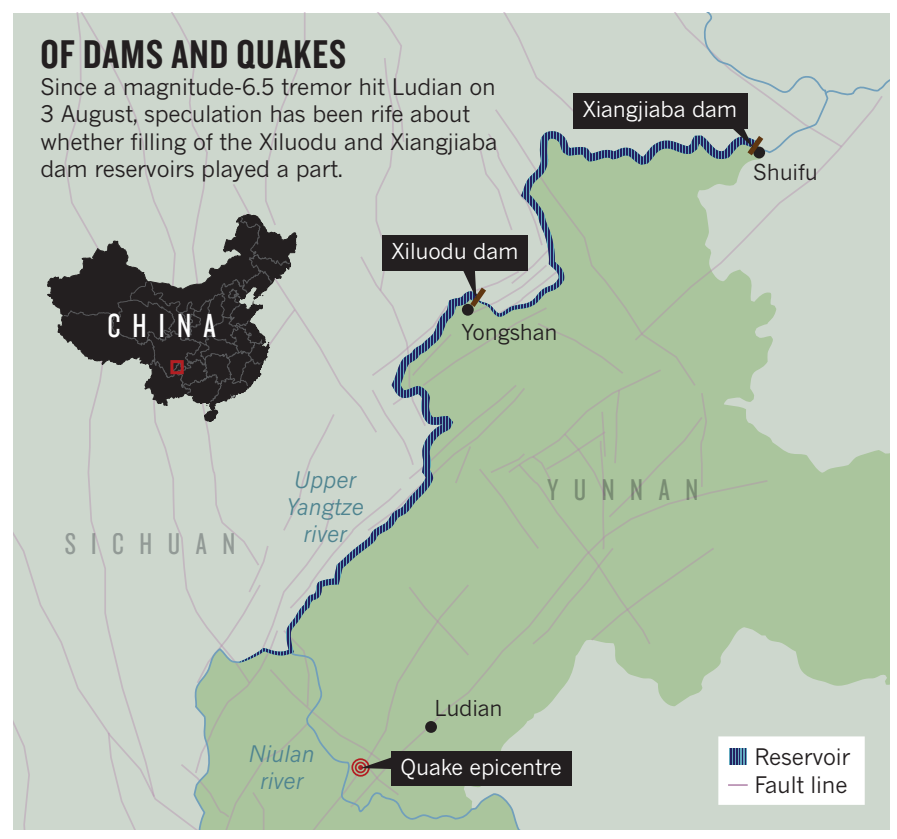

in Bronxville, New York, who studied the Wenchuan quake, says that he finds the link to the Ludian quake plausible. "You don't need water migrating into rocks to cause quakes," he says. "The sheer weight of a massive reservoir could bend Earth's crust and rupture a critically stressed fault."

Researchers including $\mathrm{Hu}$ are calling for the dissemination of more-sensitive seismic data from the dense network of stations in the reservoir areas, which are tightly controlled by hydropower companies. "This would make more detailed analyses possible," he says. Fan's analysis was based on data from seismic stations controlled by the regional government, which are sparse and have less-sensitive equipment.

With dozens more dams

Xiluodu”. The link between the Ludian quake and the reservoirs is less convincing, he says, because the epicentre is too distant and the initial rupture happened about 12 kilometres down, too deep for water to reach.

However, Christian Klose, a geologist at Think Geohazards, a consultancy firm planned or under construction for the upper Yangtze, "the issue is more pressing than ever", says Fan. Whether or not the Ludian quake was triggered by reservoir-filling, it would be prudent to prepare, says Xu. "Buildings in reservoir areas must be reinforced to fend off future quakes." 